\title{
The impact of thermal pre-conditioning on cutaneous vasomotor and shivering thresholds
}

\author{
Joanne N Caldwell, Åsa Nykvist, Nicholas Powers, Sean R Notley, Daniel S Lee, Gregory E Peoples, Nigel AS Taylor \\ From 15th International Conference on Environmental Ergonomics (ICEE XV) \\ Portsmouth, UK. 28 June - 3 July 2015
}

\section{Introduction}

The mean body temperature of resting, normothermic humans falls within the zone that separates the temperature thresholds for shivering and sweating; the vasomotor zone. Whilst these thresholds are often defined by their corresponding deep-body or mean body temperatures, it is well known that these are not set temperatures or points. Nevertheless, our knowledge concerning the factors that determine or modify these thresholds is imprecise. Therefore, the aim of this experiment was to investigate the effects of a deliberate modification of the pre-exposure mean body temperature on the subsequent vasomotor and shivering threshold temperatures. Mean body temperature was first displaced upwards, then slowly driven in the opposite direction, permitting the separate determination of these thermoeffector thresholds.

\section{Methods}

Eight males participated in two trials, each consisted of a pre-experimental, whole-body water immersion followed by passive cooling (experimental phase). Trials differed in the pre-experimental water temperature (45 min), with subjects either maintained in a normothermic (control: $34{ }^{\circ} \mathrm{C}$ ) or a heated state $\left(39{ }^{\circ} \mathrm{C}\right.$ ). Following pre-treatment and thermal clamping, subjects were passively cooled (water-perfusion garment) until 10 min beyond the onset of overt shivering. Deep-body and skin temperatures were recorded continuously, with skin blood flows (finger, forearm, calf; venous-occlusion plethysmography) and shivering (whole-body oxygen consumption) recorded during the experimental phase.

\section{Results}

Prior to cooling, mean body temperatures averaged 35.12 ${ }^{\circ} \mathrm{C}( \pm 0.2$; control $)$ and $36.74{ }^{\circ} \mathrm{C}( \pm 0.3 ; P<0.05)$. The rate of passive cooling (mean body temperature) was not different between trials: $2.16^{\circ} \mathrm{C} \cdot \mathrm{h}^{-1}( \pm 0.31$; control) and $2.15^{\circ} \mathrm{C} . \mathrm{h}^{-1}( \pm 0.21 ; P>0.05)$. In the control trial, each vasoconstrictor threshold occurred at a significantly higher mean body temperature than shivering. This was also evident following pre-heating, but now with each threshold being significantly elevated relative to the control trial. Furthermore, the shivering threshold displacement and the change in the pre-exposure mean body temperature were of an equivalent magnitude $(P>0.05)$.

\section{Discussion}

Given the level of experimental control, these threshold changes cannot be associated with between-trial differences in cooling rate. Instead, these observations are consistent with the possibility that thermoeffector thresholds may be as dependent upon the change in mean body temperature as they are upon its absolute value. Indeed, in a previous communication to this society [1], it was demonstrated that the sudomotor threshold was similarly linked with the size of the change in mean body temperature induced prior to commencing the experiment.

Published: 14 September 2015

\section{Reference}

1. Caldwell JN, Nykvist Å, Powers N, Notley SR, Lee DS, Peoples GE, Taylor NAS: An investigation of forearm vasomotor and sudomotor thresholds during passive heating, following whole-body cooling. In Proceedings of the Fourteenth International Conference on Environmental Ergonomics. Nafplio, Greece. July 10th-15th;Kounalakis, S.N., and Koskolou, M 2011:132-135.

doi:10.1186/2046-7648-4-S1-A117

Cite this article as: Caldwell et al:: The impact of thermal pre-

conditioning on cutaneous vasomotor and shivering thresholds. Extreme Physiology \& Medicine 2015 4(Suppl 1):A117. 